\title{
Pelvic retroversion: a compensatory mechanism for lumbar stenosis
}

\author{
*Sina Pourtaheri, MD, ${ }^{1}$ Akshay Sharma, BA, ${ }^{2,3}$ Jason Savage, MD,,,4 lain Kalfas, MD, ${ }^{3,5}$ \\ Thomas E. Mroz, MD, ${ }^{3,4}$ Edward Benzel, MD, ${ }^{3,5}$ and Michael P. Steinmetz, MD ${ }^{3,5}$ \\ ${ }^{1}$ Department of Orthopedic Surgery, UCLA Health, Los Angeles, California; ${ }^{2}$ Case Western Reserve University School of \\ Medicine, Cleveland; and ${ }^{3}$ Center for Spine Health, Neurological Institute, and Departments of ${ }^{4}$ Orthopedic Surgery and \\ ${ }^{5}$ Neurosurgery, Cleveland Clinic, Cleveland, Ohio
}

\begin{abstract}
OBJECTIVE The flexed posture of the proximal (L1-3) or distal (L4-S1) lumbar spine increases the diameter of the spinal canal and neuroforamina and can relieve symptoms of neurogenic claudication. Distal lumbar flexion can result in pelvic retroversion; therefore, in cases of flexible sagittal imbalance, pelvic retroversion may be compensatory for lumbar stenosis and not solely compensatory for the sagittal imbalance as previously thought. The authors investigate underlying causes for pelvic retroversion in patients with flexible sagittal imbalance.
\end{abstract}

METHODS One hundred thirty-eight patients with sagittal imbalance who underwent a total of 148 fusion procedures of the thoracolumbar spine were identified from a prospective clinical database. Radiographic parameters were obtained from images preoperatively, intraoperatively, and at 6-month and 2-year follow-up. A cohort of 24 patients with flexible sagittal imbalance was identified and individually matched with a control cohort of 23 patients with fixed deformities. Flexible deformities were defined as a $10^{\circ}$ change in lumbar lordosis between weight-bearing and non-weight-bearing images. Pelvic retroversion was quantified as the ratio of pelvic tilt (PT) to pelvic incidence (PI).

RESULTS The average difference between lumbar lordosis on supine MR images and standing radiographs was $15^{\circ}$ in the flexible cohort. Sixty-eight percent of the patients in the flexible cohort were diagnosed preoperatively with lumbar stenosis compared with only $22 \%$ in the fixed sagittal imbalance cohort $(p=0.0032)$. There was no difference between the flexible and fixed cohorts with regard to C-2 sagittal vertical axis (SVA) $(p=0.95)$ or C-7 SVA $(p=0.43)$. When assessing for postural compensation by pelvic retroversion in the stenotic patients and nonstenotic patients, the PT/PI ratio was found to be significantly greater in the patients with stenosis $(p=0.019)$.

CONCLUSIONS For flexible sagittal imbalance, preoperative attention should be given to the root cause of the sagittal misalignment, which could be compensation for lumbar stenosis. Pelvic retroversion can be compensatory for both the lumbar stenosis as well as for sagittal imbalance.

https://thejns.org/doi/abs/10.3171/2017.2.SPINE16963

KEY WORDS flat-back deformity; adult deformity; flexibility; MRI; lumbar spine; lumbar fusion; lumbar lordosis; lumbar stenosis; pelvic retroversion; sagittal imbalance

A PORTION of flexible flat-back deformity is postural, by definition. ${ }^{11,12,27,29,30,36,42}$ Patients with lumbar stenosis are known to have limited lumbar lordosis (LL) because the compensatory flexed posture helps to alleviate pain (Fig. 1).11,12,22,27-30,36,42 Flexion of the spine increases the spinal canal diameter and subsequently relieves symptoms of neurogenic claudication..$^{25,34,35,41}$ Distal lumbar flexion (L4-S1) to increase the diameter of the canal can result in pelvic retroversion (Fig. 2)..$^{25,34,35,41}$ Previously, pelvic retroversion in patients with sagittal imbalance was thought to be solely compensatory for the sagittal imbalance. $5,18,19,20,22,24,26$

A flexible flat-back deformity can result in sagittal imbalance if the patient cannot compensate for the deformity through the hips, knees, and thoracic/cervical spine..$^{5,18,24,26}$ While standing, patients will compensate to improve sta-

ABBREVIATIONS EBL = estimated blood loss; $\mathrm{LL}=$ lumbar lordosis; $\mathrm{LOS}=$ length of stay; $\mathrm{PD}-\mathrm{Q}=$ painDETECT questionnaire; PHQ-9 = Patient Health Questionnaire-9; $\mathrm{PI}=$ pelvic incidence; $\mathrm{PRO}$ = patient-reported outcome; $\mathrm{PSO}=$ pedicle subtraction osteotomy; $\mathrm{PT}$ = pelvic tilt; $\mathrm{SVA}=$ sagittal vertical axis.

SUBMITTED August 13, 2016. ACCEPTED February 9, 2017.

INCLUDE WHEN CITING Published online June 9, 2017; DOI: 10.3171/2017.2.SPINE16963.

${ }^{*}$ Dr. Pourtaheri and Mr. Sharma contributed equally to this work. 
bility by grossly flexing the spinal column both proximally and distally, resulting in a reduction of LL that quickly disappears when the patient is supine and gravitational effects are absent. ${ }^{9}$ Sagittal parameters including pelvic incidence (PI), pelvic tilt (PT), LL, and sagittal vertical axis (SVA) can be used to assess the degree of and ability for spinopelvic compensation. ${ }^{24,33,40,43}$

In a previous study, we identified a cohort of patients with radiographically evident flexible sagittal imbalance from a database of 138 patients undergoing surgery for sagittal imbalance. ${ }^{37}$ In that study, we determined that flexible sagittal imbalance was a $10^{\circ}$ change in LL between weight-bearing and non-weight-bearing images. On further analysis, we found that a significant proportion of the patients with flexible deformities were preoperatively diagnosed with lumbar stenosis when compared with a matched cohort of nonflexible patients from the same patient population (S. Pourtaheri et al: Flexible sagittal imbalance: a compensatory mechanism for lumbar stenosis, presented at the Congress of Neurological Surgeons Annual Meeting, San Diego, 2016). We hypothesize that a portion of the pelvic retroversion for flexible sagittal imbalance is compensatory for coinciding lumbar stenosis.

\section{Methods}

We retrospectively reviewed a prospective clinical database (The Knowledge Program, Cleveland Clinic) of all patients who underwent lumbar spinal fusion performed by a single fellowship-trained spine surgeon at a quaternary medical center between 2008 and 2013. Patients undergoing surgery for correction of thoracolumbar spinal deformity with symptomatic sagittal imbalance and neurological deficits were included. Patients with malignancies, infection, and fractures were excluded. All included patients required appropriate preoperative, intraoperative, and 2-year follow-up imaging. Imaging included preoperative and 6-month and 2-year postoperative full-length anteroposterior and lateral standing radiography; preoperative MRI; and intraoperative, localizing lateral lumbar radiography from L-1 to the sacrum. Preoperative lumbar stenosis was defined as significant compression of the thecal sac on axial T2-weighted MRI correlating with symptoms of neurogenic claudication. This was surgically treated via laminectomy.

Interbody fusion was only performed at the L5-S1 level and the L4-5 level because of the risk of pseudarthrosis and to maximize segmental lordosis. Other cases were above and below the pedicle subtraction osteotomy (PSO) level because of the risk of pseudarthrosis. All patients were treated with posterior-only fusion or combined anterior/posterior fusion. The anterior fusion procedure was an anterior lumbar interbody fusion. No lateral interbody fusions or open anterolateral approaches were performed.

The Knowledge Program is a patient-reported outcome (PRO) assessment tool that is partnered with our institutional electronic medical record system. It prospectively compiles self-assessment data obtained at outpatient visits. The PRO metrics used in the current study have been validated to assess patient quality of life after spinal surgery. ${ }^{44}$ The EQ-5D measures and standardizes health

\section{No Stenosis Lumbar Stenosis}

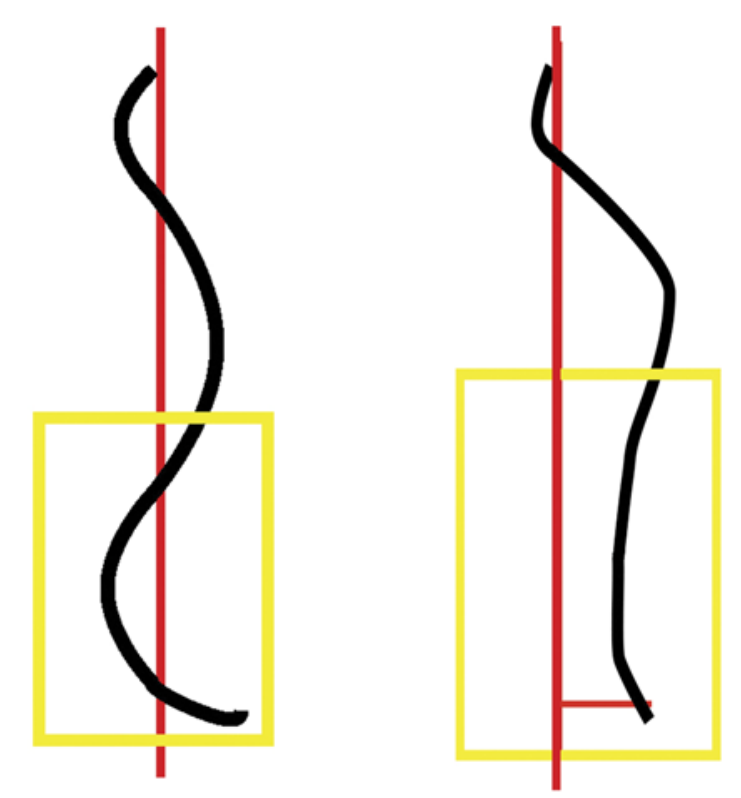

FIG. 1. Diagrams showing that compensatory lumbar flexion due to lumbar stenosis increases C-2 SVA. Figure is available in color online only.

outcomes. Scores are transformed into an index value, between 0 and 1 , known as the quality-adjusted life year, where 1 is equivalent to 1 year in perfect health and 0 is patient death. ${ }^{14}$ The painDETECT questionnaire (PD-Q), an 11-point (0-10) scale, determines how pain affects a patient's ability to function within 15 categories. It is divided into functional and psychosocial components, which are combined to give a total score (maximum 150; higher scores indicate greater disability). ${ }^{15}$ The Patient Health Questionnaire-9 (PHQ-9) screens for depression based on 9 criteria established by the Diagnostic and Statistical Manual of Mental Disorders, Fifth Edition. ${ }^{2}$ Scores between 5 and 10 indicate minor depression, and scores higher than 10 are indicative of major depression. ${ }^{19}$ The minimum clinically important differences for the EQ5D, PD-Q, and PHQ-9 values at 1 year are $0.1,26$, and 5, respectively. ${ }^{31}$ Other data such as age, sex, use of instrumentation during surgery, length of procedure, estimated blood loss (EBL), length of stay (LOS), and complications were also recorded.

A single blinded author (A.S.) performed all radiographic calculations. PI and PT were obtained from fulllength standing radiographs. LL was measured using the superior endplates of L-1 and S-1 on both the preoperative standing radiograph and the supine MR image. Flexible deformities were defined as $\mathrm{a} \geq 10^{\circ}$ mismatch between LL measured on supine MRI studies and on standing radiographs.

A control cohort $(n=23)$ comprised patients with fixed sagittal imbalance by matching for age, sex, levels fused, PI, preoperative mismatch between LL and PI, postoperative mismatch between LL and PI, EBL, length of surgery, and LOS for comparison with the flexible sagittal imbalance cases. 

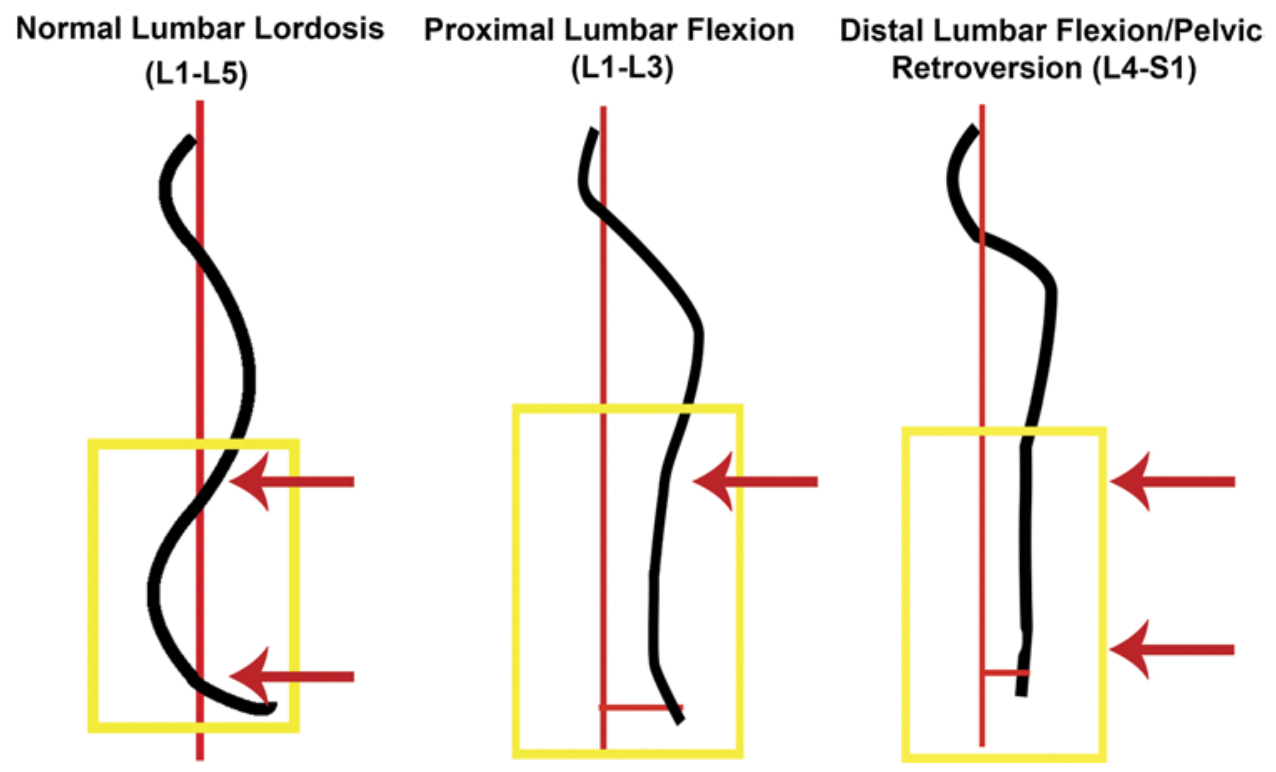

FIG. 2. The flexed posture of the proximal (L1-3) or distal (L4-S1) lumbar spine increases the diameter of the spinal canal and neuroforamina and can relieve neurogenic claudication symptoms. Distal lumbar flexion can result in pelvic retroversion; therefore, in cases of flexible sagittal imbalance, pelvic retroversion may be compensatory for lumbar stenosis and not solely compensatory for the sagittal imbalance as previously thought. Arrows indicate proximal and distal regions of flexion within the lumbar spine that provide compensation for lumbar stenosis. Figure is available in color online only.

Two authors (S.P. and A.S.) calculated preoperative global sagittal parameters in both cohorts via the C-2 and C-7 SVAs. The C-2 SVA was obtained from a full-length standing radiograph as the distance between the center point of the femoral heads to the perpendicular dropped from the center of the C-2 vertebral body. The C-7 SVA, also determined using full-length radiographs, was measured from the posterior disc space of L5-S1 to the perpendicular dropped from the center of the C-7 vertebral body. Pelvic retroversion was quantified as the PT/PI ratio.

Interobserver reliability testing was performed by 2 authors (A.S. and S.P.). These authors performed measurements using the same method described above within a 2-day period. Inter- and intraobserver reliability for all measurements were assessed using the intraclass correlation coefficient $\left.\left(\rho^{*}>0.75\right)\right)^{38}$

Frequency and percentage were used to summarize the categorical variables. The mean and standard deviation were used to summarize the continuous data after a normality assumption was validated. An unpaired Student ttest was used to examine the specific hypothesis. Ordinary least-squares regression was used to determine the association between preoperative presentation and postoperative changes measured by PROs and flexibility, procedural technique, age older than 65 years, sex, and preoperative diagnosis of stenosis with subsequent laminectomy. The model was assessed for multicollinearity and homoscedasticity. A $p$ value of $\leq 0.05$ was the threshold for significance. The STATA statistical software (version 14.0, STATACorp) was used to perform the analyses.

\section{Results}

A total of 138 patients met the inclusion criteria for surgical treatment of sagittal imbalance between 2008 and
2013. From this set of patients, 24 individuals were identified as having a flexible deformity (Table 1). The average difference between LL on supine MR images and standing radiographs was $15^{\circ}$ (range $10^{\circ}-25^{\circ}$ ), with an improvement of LL on supine MR images compared with standing radiographs.

There were no significant differences between the control cohort (fixed sagittal imbalance) and the flexible sagittal imbalance cohort for any of the chosen control parameters (Tables 1-4). There was no significant difference between the cohorts regarding the preoperative $\mathrm{C}-2$ and C-7 SVAs (Table 2). The C-2 SVA was $6.4 \mathrm{~cm}$ in the flexible cohort and $6.5 \mathrm{~cm}$ in the fixed cohort $(\mathrm{p}=0.95)$. The C-7 SVA was $11.9 \mathrm{~cm}$ and $10.4 \mathrm{~cm}$ in the flexible and fixed cohorts, respectively $(p=0.43)$. From our previous study, ${ }^{2}$ $67 \%(16 / 24)$ of the patients with flexible sagittal imbalance

TABLE 1. Demographic and clinical information for flexible and nonflexible cohorts

\begin{tabular}{lccl}
\hline \multicolumn{1}{c}{ Variable } & Flexible & Nonflexible & p Value* \\
\hline No. of patients (\%) & 24 & 23 & \\
\hline Male & $8(33)$ & $8(35)$ & 0.99 \\
\hline Female & $16(67)$ & $15(65)$ & 0.99 \\
\hline Mean age at surgery in yrs & $63.4 \pm 9.15$ & $61.5 \pm 12.92$ & 0.5632 \\
\hline Mean no. of levels fused & $9.96 \pm 2.85$ & $9.39 \pm 3.3$ & 0.5311 \\
\hline Mean EBL (L) & $1.87 \pm 1.13$ & $1.88 \pm 1.34$ & 0.9906 \\
\hline Mean length of surgery (mins) & $415 \pm 102$ & $403 \pm 84$ & 0.6656 \\
\hline Mean LOS (days) & $7.17 \pm 2.73$ & $9 \pm 1.03$ & 0.1190 \\
\hline
\end{tabular}

Mean values are presented as the mean \pm SD.

* The Student $t$-test was used for continuous variables and the Fisher exact test for categorical variables. 
TABLE 2. Radiographic parameters compared between flexible and nonflexible cohorts

\begin{tabular}{lccc}
\hline \multicolumn{1}{c}{ Parameter } & Flexible & Nonflexible & p Value* \\
\hline C-2 SVA $(\mathrm{cm})$ & $6.4 \pm 1.46$ & $6.5 \pm 2.94$ & 0.947 \\
\hline C-7 SVA $(\mathrm{cm})$ & $11.9 \pm 5.67$ & $10.4 \pm 3.62$ & 0.430 \\
\hline $\mathrm{PI}\left(^{\circ}\right)$ & $61.75 \pm 16.99$ & $63.32 \pm 14.94$ & 0.7412 \\
\hline Preop PI-LL mismatch $\left(^{\circ}\right)$ & $48.79 \pm 16.14$ & $47.86 \pm 22.33$ & 0.8716 \\
\hline Postop PI-LL mismatch $\left(^{\circ}\right)$ & $23.82 \pm 13.61$ & $19.17 \pm 15.62$ & 0.3551 \\
\hline
\end{tabular}

Mean values are presented as the mean \pm SD for categorical variables.

* The Student t-test was used to calculate significance.

had lumbar stenosis as opposed to $22 \%(5 / 23)$ of those in the fixed sagittal imbalance cohort $(\mathrm{p}=0.0032)$.

Preoperatively, the 2 cohorts (flexible vs fixed) showed no significant difference in terms of PRO on the EQ-5D and PD-Q (Table 5); however, the preoperative PHQ-9 score was significantly greater for the flexible cohort $(\mathrm{p}$ $=0.0459$ ). There was no significant association between preoperative PRO scores and age or sex. At 12 months, the flexible cohort exhibited pre- to postoperative improvement that was significant for the EQ-5D $(p=0.0026)$, PD-Q ( $p=0.0048)$, and PHQ-9 ( $\mathrm{p}=0.018)$. The fixed cohort showed no statistically significant change in preto postoperative PROs at 12 months. The flexible cohort trended toward a statistically significant improvement in PD-Q compared with the nonflexible cohort at 12 months $(\mathrm{p}=0.059)$. A preoperative diagnosis of lumbar stenosis was significantly associated with a clinically significant increase of 6.6 points $(\mathrm{p}=0.040)$ on the PHQ-9, and a preoperative radiographic diagnosis of flexible deformity was associated with a similar 6-point increase in PHQ-9 scores with a trend toward significance $(\mathrm{p}=0.051)$. No other significant associations between change in PRO scores and age older than 65 years, sex, or procedural technique were noted (Table 6).

To assess pelvic compensation, we calculated the preoperative PT/PI ratio for patients from both cohorts with and without LL. The mean PT/PI ratio for the stenotic patients was significantly greater $(0.561 \pm 0.104)$, compared with the nonstenotic patients $(0.364 \pm 0.069)(\mathrm{p}=0.019)$. Figures 3 and 4 depict a clinical example of increased pelvic retroversion in a patient with lumbar stenosis.

\section{Discussion}

A large portion of flexible flat-back deformities, with associated sagittal imbalance, is postural.,3-8,29 The study presented herein identified 24 patients with flexible sagittal imbalance. Previously, when comparing these patients to a cohort with fixed sagittal imbalance, we found that a preoperative diagnosis of lumbar spinal stenosis was significantly associated with the flexible deformities $(67 \%)$ when compared with the nonflexible deformities $(22 \%)(\mathrm{p}$ $=0.0032) .{ }^{3}$ Our findings suggested that the flat-back deformity in these cases was partially postural and compensatory for symptomatic lumbar stenosis. It is well known that a reduction in $\mathrm{LL}$ increases the canal diameter 1,7,11,17 and is usually associated with flexion of the lumbar spine, particularly from L-1 to L-3. However, caudal flexion of
TABLE 3. Surgical techniques for the flexible and nonflexible cohorts

\begin{tabular}{lrcr}
\hline \multirow{2}{*}{ Procedure } & \multicolumn{2}{c}{ No. of Patients } & \\
\cline { 2 - 3 } & Flexible & Nonflexible & p Value* \\
\hline Type of fusion & & & \\
\hline Circumferential & 15 & 14 & 0.9999 \\
\hline Posterior only & 9 & 9 & 0.9999 \\
\hline Laminectomy & 11 & 7 & 0.3715 \\
\hline PSO & 6 & 6 & 0.9999 \\
\hline Grade 1-3 osteotomy & 7 & 5 & 0.7400 \\
\hline * Student t-test. & & &
\end{tabular}

the lumbosacral junction and pelvis also helps to increase the spinal canal diameter. ${ }^{17,46}$ Distal flexion (L4-S1) results in pelvic retroversion and is associated with lumbar stenosis. ${ }^{17}$

In patients with sagittal imbalance, retroversion of the pelvis helps bring the hips forward in order to provide sagittal balance..$^{8,20,23}$ However, in patients with concomitant lumbar stenosis and sagittal imbalance, pelvic retroversion compensates for lumbar stenosis. Liu et al. found that patients with lumbar spinal stenosis had a significantly greater incidence of pelvic retroversion compared with patients with degenerative spondylolisthesis, suggesting that pelvic retroversion might help alleviate symptomatic lumbar stenosis. ${ }^{24}$ In the current study, the patients diagnosed preoperatively with lumbar stenosis had greater pelvic retroversion $(\mathrm{PT} / \mathrm{PI})$ despite having an equivalent preoperative C-7 SVA in comparison with the nonstenotic cohort $(p=0.019)$. Therefore, a portion of the pelvic retroversion is compensatory for the lumbar stenosis and not entirely compensation for the global sagittal imbalance.

For both cohorts (flexible and fixed), the C-2 and C-7 SVAs were similar. Therefore, compensatory reduction in LL for lumbar stenosis and resultant sagittal imbalance in the flexible sagittal imbalance cohort appeared to be radiographically equivalent to the fixed sagittal imbalance cohort. In many cases, standing radiographs cannot

TABLE 4. Medical complications present in the flexible and nonflexible patient cohorts

\begin{tabular}{lccl}
\hline \multicolumn{1}{c}{ Complication } & Flexible & Nonflexible & p Value* \\
\hline Atrial fibrillation & 0 & 1 & 0.99 \\
\hline Acute blood loss anemia & 5 & 2 & 0.4305 \\
\hline Urinary tract infection & 2 & 2 & 0.99 \\
\hline Metabolic acidosis & 1 & 0 & 0.99 \\
\hline Respiratory insufficiency/failure & 1 & 1 & 0.99 \\
\hline Urinary retention & 1 & 0 & 0.99 \\
\hline Delirium & 1 & 1 & 0.99 \\
\hline Pulmonary embolism & 1 & 0 & 0.99 \\
\hline Myocardial infarction & 0 & 1 & 0.99 \\
\hline Acute kidney injury & 0 & 1 & 0.99 \\
\hline Deep venous thrombosis & 0 & 1 & 0.99 \\
\hline
\end{tabular}

* Fisher exact test. 
TABLE 5. Patient-reported outcomes*

\begin{tabular}{|c|c|c|c|c|c|c|c|}
\hline \multirow[b]{2}{*}{ Metric } & \multicolumn{3}{|c|}{ Preoperative } & \multicolumn{4}{|c|}{ 12-Mo Follow-Up } \\
\hline & No. of Patients & Score & p Value & No. of Patients & Score & p Value $†$ & p Valuef \\
\hline$E Q-5 D$ & & & 0.7927 & & & & 0.31 \\
\hline Flexible & 20 & 0.441 & & 20 & 0.658 & 0.0026 & \\
\hline Nonflexible & 18 & 0.461 & & 17 & 0.58 & 0.1785 & \\
\hline$P D-Q$ & & & 0.5797 & & & & 0.0592 \\
\hline Flexible & 12 & 96.58 & & 18 & 57.5 & 0.0048 & \\
\hline Nonflexible & 13 & 90.23 & & 16 & 81.19 & 0.4354 & \\
\hline PHQ-9 & & & 0.0459 & & & & 0.5169 \\
\hline Flexible & 20 & 12.9 & & 20 & 7 & 0.018 & \\
\hline Nonflexible & 18 & 8.28 & & 18 & 8.61 & 0.8852 & \\
\hline
\end{tabular}

Boldface type indicates statistical significance.

* The matched paired t-test was used to determine significance for postoperative values compared with preoperative values. The Student $t$-test was used to determine significance for differences between flexible and nonflexible cohorts.

$\dagger$ Pre- and postoperative PRO values within the cohorts.

$\ddagger$ Difference between flexible and nonflexible cohorts.

distinguish postural sagittal imbalance from fixed sagittal imbalance. ${ }^{10,21,32}$

Clinical differentiation between flexible and fixed deformities is difficult. Standing intolerance is a common complaint in patients with both lumbar stenosis and sagittal imbalance. Symptoms have been attributed to neurogenic claudication in patients with lumbar stenosis, ${ }^{3}$ and to axial back pain in patients with sagittal imbalance. ${ }^{13}$ Furthermore, axial back pain can also be neurogenic and is associated with lumbar stenosis., ${ }^{416}$ The majority of patients with sagittal imbalance present with leg pain due to quadriceps fatigue, and the majority of patients with lumbar stenosis present with leg pain due to neurogenic claudication. . $^{3,4,16,18}$ Therefore, the clinical presentations for lumbar stenosis and sagittal imbalance often overlap. From our previous study, recommendations included using preoperative supine MRI studies in relation to the standing radiographs to determine the flexibility of sagittal imbalance. Given the difficulty in differentiating these pathologies both clinically and radiographically, supine imaging modalities can help establish whether the sagittal imbalance is fixed or postural. ${ }^{37}$
The combination of sagittal imbalance and neurogenic claudication is very disabling in comparison with sagittal imbalance alone. Yabuki et al., in an assessment of Japanese individuals between 40 and 79 years old, found a significant association between lumbar spinal stenosis and the incidence of debilitating comorbidities, including urological disorders and osteoarthritis, as well as severe depressive symptoms. ${ }^{49}$ The authors reported an adjusted odds ratio of severe depressive symptoms to be as high as 3.39. In an assessment of 100 patients with clinically diagnosed lumbar spinal stenosis, Sinikallio et al. found a significantly greater incidence of clinically significant depression (20\%) compared with that of the general population. ${ }^{39}$ In the current study, lumbar stenosis that was treated via laminectomy was associated with a clinically significant improvement in PHQ-9 scores $(p=0.04)$, indicating that identification and treatment of this pathology can significantly improve depressive symptoms for patients.

Patients with flexible sagittal deformities had superior clinical outcomes after surgery compared with the patients with fixed flat-back deformities. The superior outcomes

TABLE 6. Demographic and operative parameters associated with improvement in postoperative PROs

\begin{tabular}{|c|c|c|c|c|c|c|}
\hline Variable & $E Q-5 D$ & p Value* & $P D-Q$ & p Value* & PHQ-9 & p Value* \\
\hline Lumbar stenosis & -0.09 & 0.44 & 13 & 0.53 & 6.57 & 0.04 \\
\hline Flexible deformity & -0.08 & 0.46 & 27 & 0.24 & 5.98 & 0.05 \\
\hline Age $\geq 65$ yrs & 0.07 & 0.49 & 4 & 0.82 & -3.043 & 0.23 \\
\hline Male sex & -0.15 & & 0.44 & 0.98 & 2.53 & 0.38 \\
\hline \multicolumn{7}{|l|}{ Operative technique } \\
\hline Circumferential fusion vs posterior-only fusion & 0.02 & 0.834 & 4.9 & 0.8 & 0 & 1 \\
\hline Laminectomy & 0.2 & 0.11 & -0.53 & 0.98 & -3.21 & 0.29 \\
\hline PSO & 0.05 & 0.75 & -16 & 0.56 & -4.61 & 0.18 \\
\hline Grade 1-3 osteotomy & 0.26 & 0.07 & -22 & 0.47 & -4.91 & 0.11 \\
\hline
\end{tabular}

Boldface type indicates statistical significance.

* Ordinary least-square regression was used to determine the association between a postoperative improvement or decline in outcomes as measured by the EQ-5D, PD-Q, and PHQ-9 scales. 


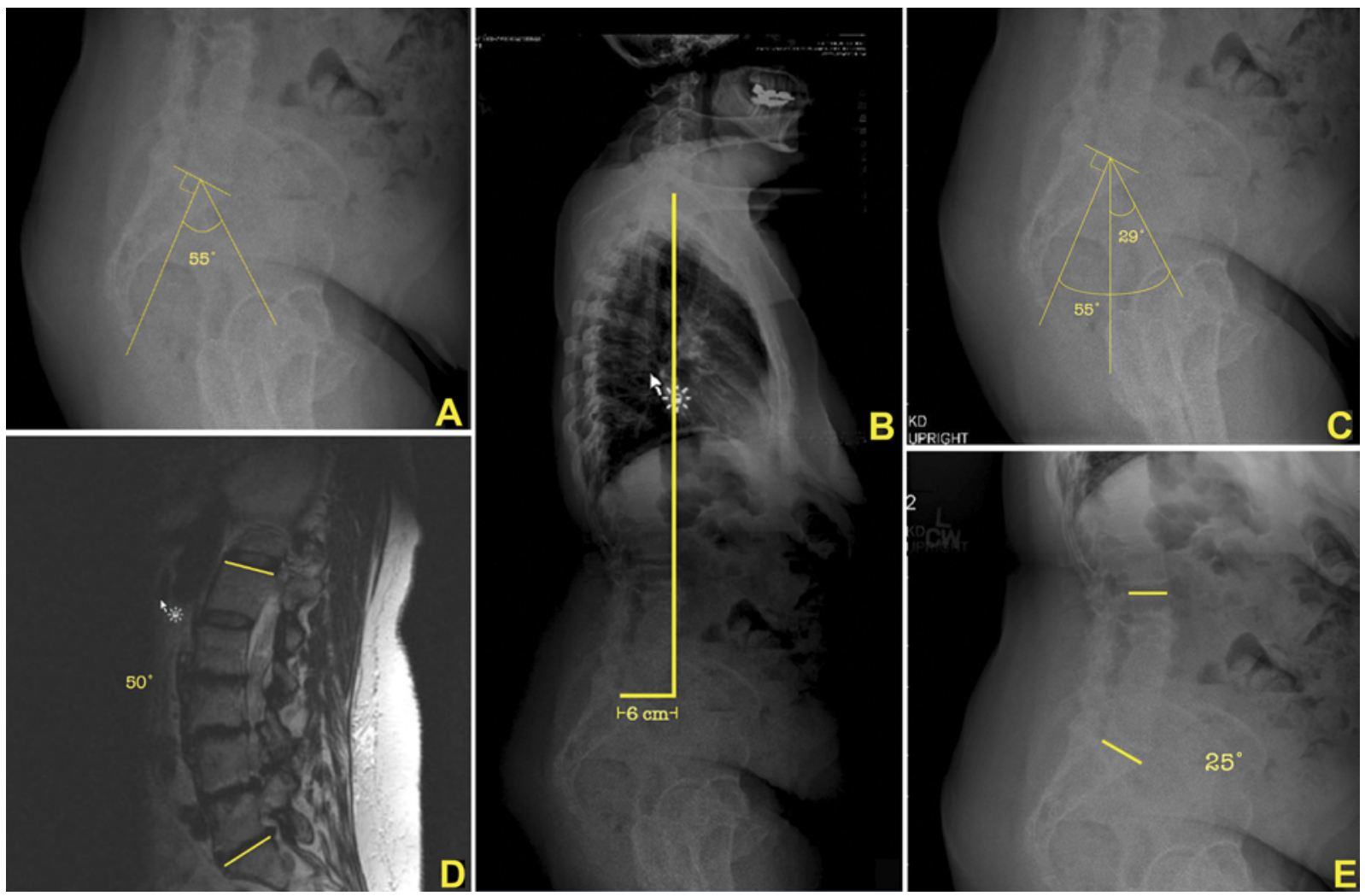

FIG. 3. Images obtained in a patient with flexible sagittal imbalance. PI (A), C-7 SVA (B), and PT (C) were measured on standing radiographs. The C-7 SVA was found to be $6 \mathrm{~cm}$ and PI-LL mismatch was $30^{\circ}$, with a $25^{\circ}$ difference between $L L$ on supine MRI (D) and standing radiography (E). Pelvic retroversion (PT/PI ratio) was 0.53 and was increased in patients with lumbar stenosis compared with those with no stenosis. Figure is available in color online only.

could be due to the fact that a significant proportion of the patients with preoperative flexible deformities had lumbar stenosis, while those with fixed deformities did not. Surgical treatment of lumbar stenosis has been shown to be a driving factor for superior outcomes and has a long track record for improvement of quality-of-life metrics. ${ }^{6,45,47,48}$ In SPORT (Spine Patients Outcomes Research Trial), the authors reported that patients with lumbar stenosis experienced significantly greater improvement with surgical treatment, compared with nonsurgical treatment in primary outcomes, including pain and function assessed postopera- tively at 2 and 4 years. ${ }^{47,48}$ With regular follow-up of more than 8-10 years in the Maine Lumbar Spine Study, Atlas et al. showed that patients with lumbar stenosis who were initially treated surgically reported less severe leg pain and had improved back-specific functional status, compared with patients treated nonsurgically. ${ }^{6}$ Furthermore, we noted that age, sex, and procedural techniques were not significantly associated with significant changes in postoperative outcomes. This further supports the hypothesis that preoperative radiological classification of sagittal imbalance contributes to favorable postoperative surgical outcomes, inde-
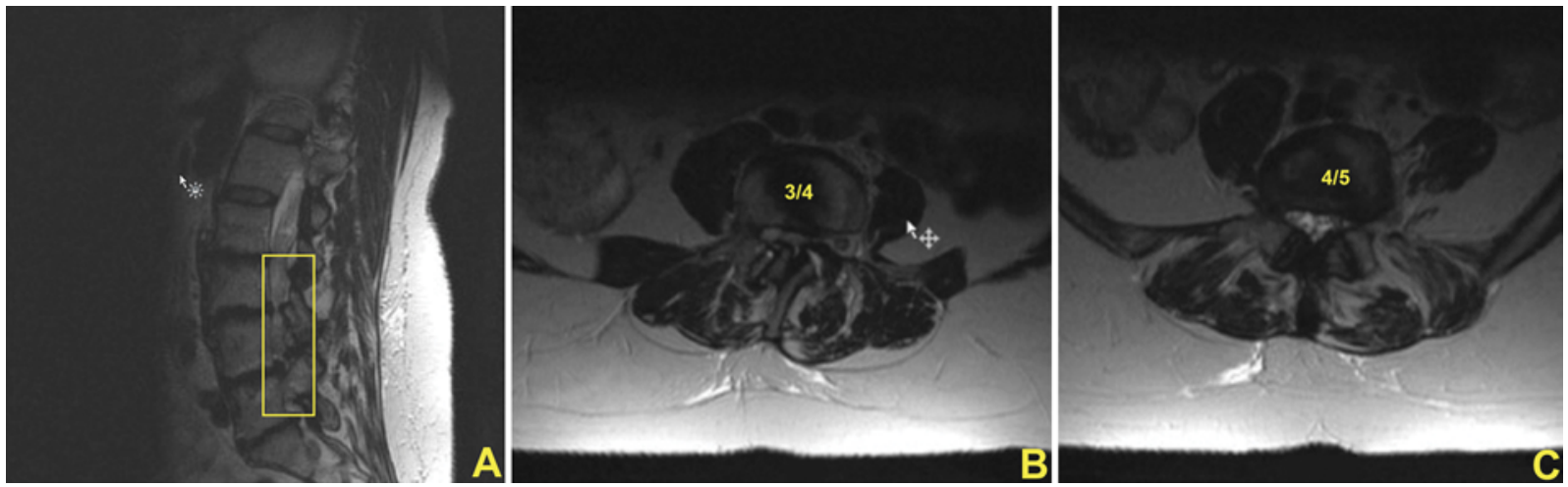

FIG. 4. Sagittal (A) and axial (B and C) MR images of lumbar stenosis at L3-5 in the same patient with flexible sagittal imbalance. Figure is available in color online only. 
pendently of factors related to sex, senescence, or operative technique.

This study is limited by several factors inherent to the chosen methodological paradigm. This study was a retrospective review of a prospective database, and as such a recall bias and selection bias may be present. Furthermore, sagittal imbalance-and even more-flexible deformity, is a relatively rare pathology, providing a small patient pool from which to draw conclusions. Larger, prospective studies of the dynamic nature of sagittal imbalance are required to fully understand the implications of our findings. Nevertheless, confidence in our findings is reinforced by the fact that our analysis matched methodologies validated in previous studies. ${ }^{15,19,31,44}$

\section{Conclusions}

Flexible sagittal imbalance can be a result of postural changes to alleviate the symptoms of lumbar stenosis. The patients with flexible sagittal imbalance had similar global sagittal parameters as those with fixed sagittal imbalance; furthermore, both patient populations have similar clinical symptoms. Lastly, a portion of the pelvic retroversion can be compensatory for lumbar stenosis as well as for sagittal imbalance.

\section{References}

1. Abbas J, Hamoud K, May H, Hay O, Medlej B, Masharawi Y, et al: Degenerative lumbar spinal stenosis and lumbar spine configuration. Eur Spine J 19:1865-1873, 2010

2. American Psychiatric Association: Diagnostic and Statistical Manual of Mental Disorders, ed 5. Arlington, VA: American Psychiatric Association, 2013

3. Amundsen T, Weber H, Lilleås F, Nordal HJM, Abdelnoor M, Magnaes B: Lumbar spinal stenosis. Clinical and radiologic features. Spine (Phila Pa 1976) 20:1178-1186, 1995

4. Arbit E, Pannullo S: Lumbar stenosis: a clinical review. Clin Orthop Relat Res (384):137-143, 2001

5. Asai H, Tsuchiyama H, Hatakeyama T, Inaoka PT, Murata $\mathrm{K}$ : Age-related changes in maximum pelvic anteversion and retroversion angles measured in the sitting position. J Phys Ther Sci 26:1959-1961, 2014

6. Atlas SJ, Keller RB, Wu YA, Deyo RA, Singer DE: Longterm outcomes of surgical and nonsurgical management of lumbar spinal stenosis: 8 to 10 year results from the Maine Lumbar Spine Study. Spine (Phila Pa 1976) 30:936-943, 2005

7. Barrey C, Jund J, Noseda O, Roussouly P: Sagittal balance of the pelvis-spine complex and lumbar degenerative diseases. A comparative study about 85 cases. Eur Spine J 16:14591467,2007

8. Barrey C, Jund J, Perrin G, Roussouly P: Spinopelvic alignment of patients with degenerative spondylolisthesis. Neurosurgery 61:981-986, 2007

9. Bridwell KH, Lenke LG, Lewis SJ: Treatment of spinal stenosis and fixed sagittal imbalance. Clin Orthop Relat Res (384):35-44, 2001

10. Cho KJ, Kim KT, Kim WJ, Lee SH, Jung JH, Kim YT, et al: Pedicle subtraction osteotomy in elderly patients with degenerative sagittal imbalance. Spine (Phila Pa 1976) 38:E1561E1566, 2013

11. Endo K, Suzuki H, Tanaka H, Kang Y, Yamamoto K: Sagittal spinal alignment in patients with lumbar disc herniation. Eur Spine J 19:435-438, 2010

12. Enomoto M, Ukegawa D, Sakaki K, Tomizawa S, Arai Y,
Kawabata S, et al: Increase in paravertebral muscle activity in lumbar kyphosis patients by surface electromyography compared with lumbar spinal canal stenosis patients and healthy volunteers. J Spinal Disord Tech 25:E167-E173, 2012

13. Epstein JA, Epstein BS, Jones MD: Symptomatic lumbar scoliosis with degenerative changes in the elderly. Spine (Phila Pa 1976) 4:542-547, 1979

14. EuroQol Group: EuroQol-a new facility for the measurement of health-related quality of life. Health Policy 16:199_ 208, 1990

15. Freynhagen R, Baron R, Gockel U, Tölle TR: painDETECT: a new screening questionnaire to identify neuropathic components in patients with back pain. Curr Med Res Opin 22:1911-1920, 2006

16. Hall S, Bartleson JD, Onofrio BM, Baker HL Jr, Okazaki H, O'Duffy JD: Lumbar spinal stenosis. Clinical features, diagnostic procedures, and results of surgical treatment in 68 patients. Ann Intern Med 103:271-275, 1985

17. Inufusa A, An HS, Lim TH, Hasegawa T, Haughton VM, Nowicki BH: Anatomic changes of the spinal canal and intervertebral foramen associated with flexion-extension movement. Spine (Phila Pa 1976) 21:2412-2420, 1996

18. Jang JS, Lee SH, Min JH, Maeng DH: Changes in sagittal alignment after restoration of lower lumbar lordosis in patients with degenerative flat back syndrome. J Neurosurg Spine 7:387-392, 2007

19. Kroenke K, Spitzer RL, Williams JB: The PHQ-9: validity of a brief depression severity measure. J Gen Intern Med 16:606-613, 2001

20. Lafage V, Smith JS, Bess S, Schwab FJ, Ames CP, Klineberg E, et al: Sagittal spino-pelvic alignment failures following three column thoracic osteotomy for adult spinal deformity. Eur Spine J 21:698-704, 2012

21. Le Huec JC, Charosky S, Barrey C, Rigal J, Aunoble S: Sagittal imbalance cascade for simple degenerative spine and consequences: algorithm of decision for appropriate treatment. Eur Spine J 20 (Suppl 5):699-703, 2011

22. Lee JH, Kim KT, Suk KS, Lee SH, Jeong BO, Kim JS, et al: Analysis of spinopelvic parameters in lumbar degenerative kyphosis: correlation with spinal stenosis and spondylolisthesis. Spine (Phila Pa 1976) 35:E1386-E1391, 2010

23. Legaye J, Duval-Beaupère G, Hecquet J, Marty C: Pelvic incidence: a fundamental pelvic parameter for three-dimensional regulation of spinal sagittal curves. Eur Spine J 7:99-103, 1998

24. Liu H, Li S, Zheng Z, Wang J, Wang H, Li X: Pelvic retroversion is the key protective mechanism of L4-5 degenerative spondylolisthesis. Eur Spine J 24:1204-1211, 2015

25. Magnaes B: Clinical recording of pressure on the spinal cord and cauda equina. Part 2: position changes in pressure on the cauda equina in central lumbar spinal stenosis. J Neurosurg 57:57-63, 1982

26. Mendoza-Lattes SA, Ries Z, Goo Y, Weinstein S: Pelvic retroversion determines a reciprocal relationship between pelivic incidence and sacral slope in advanced degenerative disease of the spine. Spine (Phila Pa 1976) 10:131, 2009 (Abstract)

27. Miyakoshi N, Hongo M, Kasukawa Y, Ishikawa Y, Shimada Y: Prevalence, spinal alignment, and mobility of lumbar spinal stenosis with or without chronic low back pain: a community-dwelling study. Pain Res Treat 2011:340629, 2011

28. Miyazaki M, Hong SW, Yoon SH, Zou J, Tow B, Alanay A, et al: Kinematic analysis of the relationship between the grade of disc degeneration and motion unit of the cervical spine. Spine (Phila Pa 1976) 33:187-193, 2008

29. Miyazaki M, Hymanson HJ, Morishita Y, He W, Zhang H, Wu G, et al: Kinematic analysis of the relationship between 
sagittal alignment and disc degeneration in the cervical spine. Spine (Phila Pa 1976) 33:E870-E876, 2008

30. Panjabi MM: Clinical spinal instability and low back pain. J Electromyogr Kinesiol 13:371-379, 2003

31. Parker SL, Godil SS, Shau DN, Mendenhall SK, McGirt MJ: Assessment of the minimum clinically important difference in pain, disability, and quality of life after anterior cervical discectomy and fusion: clinical article. J Neurosurg Spine 18:154-160, 2013

32. Roussouly P, Gollogly S, Berthonnaud E, Dimnet J: Classification of the normal variation in the sagittal alignment of the human lumbar spine and pelvis in the standing position. Spine (Phila Pa 1976) 30:346-353, 2005

33. Schwab F, Lafage V, Patel A, Farcy JP: Sagittal plane considerations and the pelvis in the adult patient. Spine (Phila Pa 1976) 34:1828-1833, 2009

34. Schönström N, Hansson T: Pressure changes following constriction of the cauda equina. An experimental study in situ. Spine (Phila Pa 1976) 13:385-388, 1988

35. Schönström N, Lindahl S, Willén J, Hansson T: Dynamic changes in the dimensions of the lumbar spinal canal: an experimental study in vitro. J Orthop Res 7:115-121, 1989

36. Schroeder J, Schaar H, Mattes K: Spinal alignment in low back pain patients and age-related side effects: a multivariate cross-sectional analysis of video rasterstereography back shape reconstruction data. Eur Spine J 22:1979-1985, 2013

37. Sharma A, Pourtaheri S, Savage J, Kalfas I, Benzel E, Mroz T, et al: MRI for flexible sagittal imbalance. Neurosurg Focus 40(4):A22, 2016 (Abstract)

38. Shrout PE, Fleiss JL: Intraclass correlations: uses in assessing rater reliability. Psychol Bull 86:420-428, 1979

39. Sinikallio S, Aalto T, Airaksinen O, Herno A, Kröger H, Savolainen S, et al: Depression and associated factors in patients with lumbar spinal stenosis. Disabil Rehabil 28:415422, 2006

40. Smith JS, Klineberg E, Schwab F, Shaffrey CI, Moal B, Ames CP, et al: Change in classification grade by the SRSSchwab Adult Spinal Deformity Classification predicts impact on health-related quality of life measures: prospective analysis of operative and nonoperative treatment. Spine (Phila Pa 1976) 38:1663-1671, 2013

41. Sortland O, Magnaes B, Hauge T: Functional myelography with metrizamide in the diagnosis of lumbar spinal stenosis. Acta Radiol Suppl 355:42-54, 1977

42. Sung PS, Lammers AR, Danial P: Different parts of erector spinae muscle fatigability in subjects with and without low back pain. Spine J 9:115-120, 2009

43. Terran J, Schwab F, Shaffrey CI, Smith JS, Devos P, Ames $\mathrm{CP}$, et al: The SRS-Schwab adult spinal deformity classification: assessment and clinical correlations based on a pro- spective operative and nonoperative cohort. Neurosurgery 73:559-568, 2013

44. Tharin S, Mayer E, Krishnaney A: Lumbar microdiscectomy and lumbar decompression improve functional outcomes and depression scores. Evid Based Spine Care J 3:65-66, 2012

45. Tosteson ANA, Lurie JD, Tosteson TD, Skinner JS, Herkowitz H, Albert T, et al: Surgical treatment of spinal stenosis with and without degenerative spondylolisthesis: cost-effectiveness after 2 years. Ann Intern Med 149:845-853, 2008

46. Wei F, Wang J, Zou J, Hong SW, Zhang H, He W, et al: Effect of lumbar angular motion on central canal diameter: positional MRI study in 491 cases. Chin Med J (Engl) 123:1422-1425, 2010

47. Weinstein JN, Tosteson TD, Lurie JD, Tosteson A, Blood E, Herkowitz H, et al: Surgical versus nonoperative treatment for lumbar spinal stenosis four-year results of the Spine Patient Outcomes Research Trial. Spine (Phila Pa 1976) 35:1329-1338, 2010

48. Weinstein JN, Tosteson TD, Lurie JD, Tosteson ANA, Blood E, Hanscom B, et al: Surgical versus nonsurgical therapy for lumbar spinal stenosis. N Engl J Med 358:794-810, 2008

49. Yabuki S, Fukumori N, Takegami M, Onishi Y, Otani K, Sekiguchi M, et al: Prevalence of lumbar spinal stenosis, using the diagnostic support tool, and correlated factors in Japan: a population-based study. J Orthop Sci 18:893-900, 2013

\section{Disclosures}

The authors report the following. Dr. Savage: consultant for Stryker Spine. Dr. Kalfas: patent holder with Mako Surgical and stock warrants from Paradigm Spine. Dr. Mroz: ownership in PearlDiver, and consultant for Stryker and Ceramtech. Dr. Steinmetz: consultant for Biomet Spine and Intelirod; and honoraria from Globus, Stryker Spine, and DePuy.

\section{Author Contributions}

Conception and design: all authors. Acquisition of data: Sharma. Analysis and interpretation of data: Pourtaheri, Sharma. Drafting the article: Pourtaheri, Sharma. Critically revising the article: Pourtaheri, Sharma, Savage, Kalfas, Mroz, Steinmetz. Reviewed submitted version of manuscript: all authors. Approved the final version of the manuscript on behalf of all authors: Pourtaheri. Statistical analysis: Sharma, Benzel. Study supervision: Pourtaheri.

\section{Correspondence}

Sina Pourtaheri, Department of Orthopaedic Surgery, UCLA, 1250 16th St., Ste. 3145B, Santa Monica, CA 90404. email: spourtaheri@mednet.ucla.edu. 